\title{
TÁCH CHIẾT, TINH SẠCH VÀ NGHIÊN CÚU ĐẶC ĐIỂM CỦA KHÁNG SINH TỬ XẠ KHUẪN STREPTOMYCES SP. QN63 CHỐNG STAPHYLOCOCCUS AUREUS NHÒ̀N KHÁNG SINH
}

\author{
Dương Minh Lam*, Đặng Ngọc Quang, Nguyễn Thị Hà \\ Truờng Đại học Su phạm Hà Nội, 136 Xuân Thuỷ, Cầu Giấy, Hà Nội \\ *Email: duong.minhlam@gmail.com
}

Đến Tòa soạn: 8/9/2012; Chấp nhận đăng: 6/11/2013

\begin{abstract}
TÓM TẮT
Xạ khuẩn Streptomyces sp. QN63 phân lập được từ đất rừng ngập mặn Yên Hưng, Quảng Ninh có khả năng kháng mạnh Staphylococcus aureus nhờn kháng sinh. Kháng sinh do chủng xạ khuẩn này sinh ra đã được đánh giá là có khả năng chịu nhiệt. Trong nghiên cứu này, chúng tôi đã sử dụng các phương pháp vi sinh và hóa sinh để xác định phổ kháng khuẩn và nấm của kháng sinh do Streptomyces sp. QN63 sinh ra và các quá trình tách chiết, tinh sạch kháng sinh trên. Kết quả cho thấy kháng sinh nghiên cứu kháng được cả hai loại vi khuẩn Gram âm và Gram dương, nhưng không biểu hiện hoạt tính kháng lại các nấm kiểm định nghiên cứu. Kết quả phân tích phổ cộng hưởng từ hạt nhân $\mathrm{H}$ và $\mathrm{C} 13$ chỉ ra rằng đây là một kháng sinh peptide vòng. So sánh với ngân hàng dữ liệu các hợp chất có hoạt tính, kháng sinh này có thể là một kháng sinh mới.
\end{abstract}

Tù khóa: Streptomyces sp. QN63, Staphylococcus aureus, nhờn kháng sinh, kháng sinh mới.

\section{MỞ ĐẦU}

Nghiên cứu tìm kháng sinh mới luôn được các nhà khoa học trên toàn thế giới quan tâm. Hiện nay, mặc dù đã có hơn 10000 loại kháng sinh được công bố nhưng cuộc tìm kiếm này vẫn ngày càng sôii động [1]. Sự xuất hiện ngày càng nhiều các chủng vi khuẩn nhờn các kháng sinh cũng như các bệnh nan y của thời đại như ung thư, các bệnh vi rút mà điển hình là HIV - vẫn chưa có dược liệu hiệu nghiệm để chữa trị, chính là động lực thúc đẩy các nhà khoa học không ngừng nghiên cứu nhằm tìm ra các phương pháp và dược phẩm hiệu nghiệm để giải quyết vấn đề cấp bách đó [2].

Vi khuẩn Staphylococcus aureus kháng methicillin (Methicillin Resistant Staphylococcus aureus-MRSA) là vấn đề toàn cầu khi chúng kháng phần lớn các loại kháng sinh đã và đang được sử dụng. Mức độ gia tăng về số lượng các chủng có khả năng kháng kháng sinh nhanh tới mức báo động. Năm 1991, hơn một nửa các chủng vi khuẩn $S$. aureus gây nhiễm ở Mỹ có khả năng kháng lại penicillin, methicillin, tetracycline, và erythromycin. Tại thời điểm đó vancomycin kháng sinh duy nhất còn hiệu lực cao với vi khuẩn này. Tuy nhiên, năm 1996, Nhật 
Bản, Pháp, Anh và Mỹ đã lần lượt công bố phát hiện $S$. aureus kháng vancomycin nồng độ $4-8 \mu \mathrm{g} / \mathrm{ml}$ [3]. Mức độ kháng tăng nhanh khi năm 2002 các nhà khoa học Mỹ đã tìm thấy S. aureus kháng vancomycin nồng độ $16 \mu \mathrm{g} / \mathrm{ml}$ [4]. Hiện $S$. aureus đã nhiễm gần $1 / 3$ dân số thế giới, do vậy, những thuốc kháng sinh truyền thống có lẽ không giải quyết được" [5].

Trong nghiên cứu trước đây, chúng tôi đã tuyển chọn được chủng xạ khuẩn Streptomyces sp. QN63 có khả năng sinh kháng sinh chống lại $S$. aureus nhờn kháng sinh. Một số đặc điểm sinh kháng sinh của chủng xạ khuẩn này đã được nghiên cứu. Trong nghiên cứu này, chúng tôi sẽ báo cáo về kết quả nghiên cứu tách chiết, tinh sạch và một số đặc điểm của kháng sinh cho chủng Streptomyces sp. QN63 sinh ra.

\section{VậT LIỆU VÀ PHƯƠNG PHÁP NGHIÊN CÚU}

\subsection{Vật liệu}

- Đối tương nghiên cưu: Chủng xạ khuẩn Streptomyces sp. QN63 phân lập được từ đất RNM huyện Yên Hưng tỉnh Quảng Ninh.

- VSVKÐ: V. parahaemolyticus (VSV KĐ 1), S. aureus 30sd (VSV KĐ 2), S. cholerasuis (VSV KĐ 3), B. subtilis VSV KĐ 4) được cung cấp từ phòng Vi sinh vật học, Viện Vệ sinh dịch tễ Trung Ương và Aspergillus niger, Penicillium sp. và Candida albicans từ bộ sưu tập giống Bộ môn CNSH-Vi sinh, Trường ĐHSP Hà Nội.

- Môi trường A9 (glucose $10 \mathrm{~g}$, pepton $5 \mathrm{~g}$, rỉ đường $20 \mathrm{~g}$, nước biển $1000 \mathrm{ml}, \mathrm{pH}=7$ ).

\subsection{Phương pháp nghiên cứu}

\subsubsection{Chiết rút kháng sinh}

Streptomyces sp. QN63 được nuôi trong môi trường A9 trong 120 giờ sau đó lấy dịch đem li tâm 10.000 v/phút trong 5 phút, tách sinh khối và dịch. Phần dịch được sử dụng để tách kháng sinh thô bằng các dung môi khác nhau như sau (dịch nuôi cấy : dung môi) : ethylacetate với tỉ lệ $1,5: 5$; acetone với tỉ lệ $1: 4$; và etanol với tỉ lệ $1: 4$. Tất cả các thí nghiệm đều được lắc trong 4 giờ, tách phần dung môi phía trên và dưới. Dùng máy cất quay cất phần dung môi phía trên thu kháng sinh thô đậm đặc. Sau khi thu được kháng sinh thô đậm đặc, pha với nước cất $1 / 10$ thể tích của dịch nuôi cấy đã sử dụng.

\subsubsection{Tinh sạch kháng sinh}

Sắc kí bản mỏng (TLC) [6]

Kháng sinh thô sau khi chiết được hòa tan trong ethylacetate với tỉ lệ $1 / 10$. Cắt các bản mỏng (Kieselgel $60 \mathrm{~F} 254$, của hãng Merck) thành có kích thước $1 \times 7(\mathrm{~cm})$ và kẻ đường xuất phát cách mép dưới bản mỏng $1 \mathrm{~cm}$, đường đích cách mép trên bản mỏng $1 \mathrm{~cm}$. Chấm $50 \mu \mathrm{l}$ dịch kháng sinh vào chính giữa vạch đích và chạy ở các hệ dung môi: ethylacetate, chloroform : methanol (10:1) chloroform : methanol (20:1), chloroform: methanol (30:1), methanol $2 \%$ trong ethylacetate, methanol $5 \%$ trong ethylacetate. Các bản sắc kí được soi dưới đèn tử ngoại Carmaz ở 2 bước sóng là: $254 \mathrm{~nm}$ và $366 \mathrm{~nm}$ rồi phun thuốc thử $\mathrm{H}_{2} \mathrm{SO}_{4}$ trong metanol và sấy ở $100{ }^{\circ} \mathrm{C}$ để phát hiện các hợp chất. Xác định vị trí các vạch dừng của dung môi và các vệt kháng sinh, tính giá trị Rf. 


\section{Phwơng pháp sắc kí cột [7]}

Nhồi và cân bằng cột bằng dung môi được lựa chọn sử dụng hạt silicagel 60 - $100 \mu \mathrm{m}$ (Merck). Trộn mẫu và hạt silicagel vào cùng dung môi, sau đó để dung môi bay hết và nghiền hỗn hợp thành bột mịn. Đưa hỗn hợp này vào cột để tạo thành một lớp trên bề mặt cột silicagel. Cho dung môi vào cột đồng thời mở vòi điều chỉnh dung môi chảy ra với một tốc độ $5 \mathrm{ml} /$ phút. Hứng $2 \mathrm{ml}$ dịch chảy ra vào mỗi ống nghiệm, đánh số thứ tự. Bổ sung thêm dung môi đến khi chất thử chảy ra hết. Kiểm tra hoạt tính kháng sinh của từng phân đoạn thu được và tiến hành chạy TLC mẫu ở mỗi ống nghiệm, sau đó gộp các ống có hoạt tính và có cùng giá trị Rf (các phân đoạn).

\subsubsection{Xác định cấu trúc kháng sinh}

Phổ cộng hưởng từ proton ${ }^{1} \mathrm{H}-\mathrm{NMR}$ và cacbon ${ }^{13} \mathrm{C}$ NMR-Thiết bị đo cộng hưởng từ hạt nhân Brucker Avance $500 \mathrm{MHz}$ (Một chiều ${ }^{1} \mathrm{H}$ NMR và ${ }^{13} \mathrm{C}$ NMR trong dung môi $\mathrm{CDCl}_{3}$ tại phòng nghiên cứu cấu trúc, Viện Hóa học, Viện Hàn lâm Khoa học và Công nghệ Việt Nam). Chuẩn bị chất thử: cân khoảng $10 \mathrm{mg}$ mẫu hòa tan vào $0,4 \mathrm{ml}$ dung môi $\mathrm{CDCl}_{3}$ sau đó chuyển toàn bộ dung dịch vào ống đo phổ cộng hưởng từ hạt nhân. Tiến hành đo mẫu và thu kết quả phổ. Sau đó giải phổ để xác định cấu trúc của mẫu [8].

Phổ khối FT-ICR-MS đo trên máy Varian 910 - MS TQFTMS - 7 Tesla Viện Hóa học, Viện Hàn lâm Khoa học và Công nghệ Việt Nam.

\section{KẾT QUẢ VÀ THẢO LUẬN}

\subsection{Phổ kháng khuẩn của kháng sinh}

Kết quả nghiên cứu cho thấy dung môi ethylacetate là phù hợp hơn cả trong việc tách chiết và cô đặc kháng sinh từ chủng xạ khuẩn nghiên cứu. Dịch chiết thô kháng sinh từ Streptomyces sp. QN63 sử dụng dung môi ethylacetate $(1,5: 5)$ được sử dụng để nghiên cứu khả năng kháng khuẩn Gram âm và Grram dương và kháng nấm. Kết quả nghiên cứu được thể hiện trong bảng 1 .

Bảng 1. Phổ kháng khuẩn và nấm của kháng sinh từ Streptomyces sp. QN63.

\begin{tabular}{|c|c|c|c|c|c|c|}
\hline \multicolumn{7}{|c|}{ Hoạt tính kháng sinh (D - d, cm) } \\
\hline $\begin{array}{c}\text { V. parahae- } \\
\text { molyticus }\end{array}$ & $\begin{array}{c}\text { S. aureus } \\
30 \mathrm{sd}\end{array}$ & S. cholerasuis & B. subtilis & A. niger & Penicillium sp. & C. albicans \\
\hline 3,0 & 2.8 & 2.2 & 3.1 & - & - & - \\
\hline
\end{tabular}

Kháng sinh do chủng xạ khuẩn Streptomyces sp. QN63 sinh ra thể hiện hoạt tính ức chế tất cả các vi khuẩn kiểm định sử dụng trong nghiên cứu này, trong đó có hai vi khuẩn Gram dương (S. aureus và $B$. subtilis) và hai vi khuẩn Gram âm (Vibrio parahaemolyticus và Salmonella cholerasuis) nhưng hoàn toàn không thể hiện hoạt tính trên 03 loại nấm kiểm định (Aspergillus niger, Penicillium sp. và Candida albicans). Kết quả nghiên cứu chứng tỏ là kháng sinh từ Streptomyces sp. QN63 có kháng khuẩn phổ rộng (hình 1).

Kết quả nghiên cứu phổ kháng khuẩn và kháng nấm trên sẽ hỗ trợ cho việc định hướng nhóm cấu trúc của kháng sinh nghiên cứu. Do xạ khuẩn Streptomyces sp. QN63 không biểu hiện 
hoạt tính kháng nấm nên chúng tôi có thể xác định kháng sinh từ chủng Streptomyces sp. QN63 sẽ không thuộc các nhóm kháng sinh chống nấm như polyene, allylamine, fluconazole, ketonazole, itraconazole hoặc posaconazole. Kháng sinh do Streptomyces sp. QN63 sinh ra cũng khác so với kháng sinh từ $S$. alboflavus PU23, có khả năng kháng nấm [9].

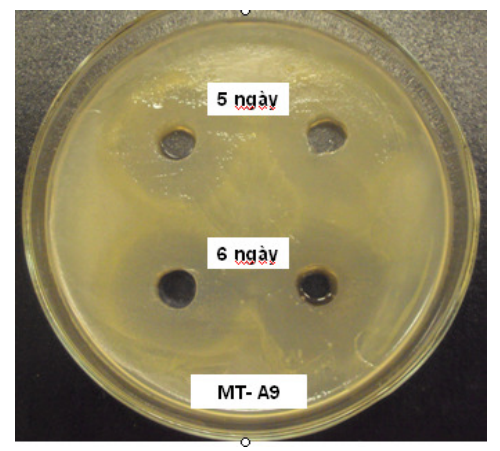

S. aureus 30sd

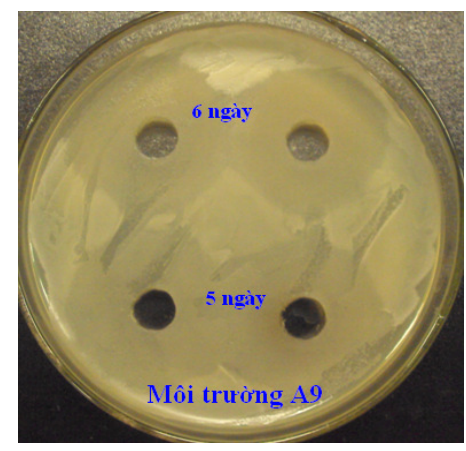

Vibrio parahaemolyticus

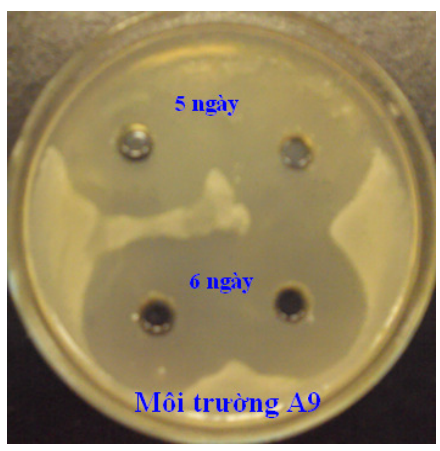

Bacillus subtilis

Hình 1. Khả năng kháng một số VSV KĐ của kháng sinh từ Streptomyces sp. QN63.

\subsection{Lựa chọn hệ dung môi tách chiết kháng sinh}

Kết quả nghiên cứu hệ dung môi được sử dụng để nghiên cứu khả năng tách kháng sinh ra khỏi dịch chiết kháng sinh thô được trình bày trong bảng 2 và mô phỏng trên hình 2 .

Bảng 2. Khả năng phân tách kháng sinh của các hệ dung môi khác nhau trên TLC.

\begin{tabular}{|l|l|c|c|c|c|}
\hline \multirow{2}{*}{ STT } & \multicolumn{2}{|c|}{ Hệ dung môi sử dụng } & \multicolumn{4}{c|}{ Giá tri Rf } \\
\cline { 3 - 6 } & & Rf 1 & Rf 2 & Rf3 & Rf4 \\
\hline 1 & Ethylacetate & $2 / 5$ & & & \\
\hline 2 & Chloroform: Methanol (30:1) & $1 / 5$ & $2,6 / 5$ & $4,5 / 5$ & \\
\hline 3 & Chloroform: Methanol (20:1) & $4,4 / 5$ & & & \\
\hline 4 & Chloroform: Methanol (10:1) & $0 / 5$ & $1 / 5$ & $1,6 / 5$ & $3,5 / 5$ \\
\hline 5 & Methanol 5 \% trong ethylacetate & $2,2 / 5$ & $3,5 / 5$ & & \\
\hline 6 & Methanol 2 \% trong ethylacetate & $2 / 5$ & & & \\
\hline
\end{tabular}

Khi chạy dung môi ethylacetate mẫu thử tách thành 1 vết dài với giá trị $\operatorname{Rf} 1=2 / 5$. Vệt tách trải dài nên dễ lẫn tạp chất trong quá trình rửa giải, do vậy dung môi này không phù hợp cho việc chạy sắc kí cột.

Trong hệ dung môi chloroform: metanol (20:1) các vệt tách có các giá trị Rf1 $=1 / 5, \operatorname{Rf} 2=$ $2,6 / 5, \operatorname{Rf} 3=4,5 / 5$. Mặc dù các chất trong mẫu thử đã được tách ra, nhưng giá trị Rf3 quá gần vạch đích, do đó thời gian rửa giải nhanh, dễ lẫn các tạp chất, không sử dụng hệ dung môi này để chạy sắc kí cột. 
Ở hai hệ dung môi chlororm: metanol $(10: 1)$ và $2 \%$ methanol trong ethylacetate đều thu được 1 giá trị Rf duy nhất tương ứng là $=4,4 / 5$ và $=2 / 5$, do đó không sử dụng hai hệ dung môi này cho chạy sắc kí cột.

Trong hệ dung môi chloroform: metanol (30:1) có Rf1 = 0/5, Rf2 = 1/5, Rf3 = 1,6/5, Rf4 = $3,5 / 5$. Ở hệ dung môi này, các vệt kháng sinh đã tách rời nhau ra, tuy nhiên vạch thứ nhất đã không di chuyển, vạch thứ 2 ở gần đường xuất phát nên thời gian rửa giải nhanh, dễ bị lẫn các chất tạp.
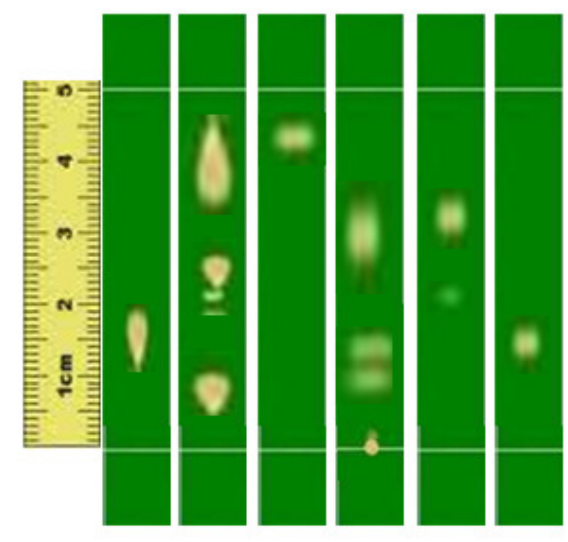

\section{Vạch đích}

$\begin{array}{lllll}\text { (1) } & \text { (2) } & \text { (3) } & \text { (4) } & \text { (5) }\end{array}$

Hình 2. Mô phỏng kết quả TLC với các hệ dung môi khác nhau.

Với hệ dung môi methanol $5 \%$ trong ethylacetate có 2 giá trị Rf tương ứng $\operatorname{Rf} 1=2,2 / 5$ và $\mathrm{Rf} 2=3,5 / 5$. Ở hệ dung môi này thời gian rửa giải vừa phải, 2 vệt cách xa nhau nên hiệu quả tách cao.

Như vậy, hệ dung môi thích hợp là methanol $5 \%$ trong ethylacetate sẽ được sử dụng để tách các chất kháng sinh từ chủng Streptomyces sp. QN63. Hệ dung môi này được dùng cho sắc kí cột để tách và tinh sạch các tiểu phần kháng sinh trong dịch kháng sinh thô.

\subsection{Tách chiết, tinh sạch kháng sinh}

Cột sắc kí được chạy với dung môi methanol $5 \%$ trong ethylacetate với áp suất bình thường. Tốc độ rửa cột $5 \mathrm{ml} / \mathrm{phút}$, thu dịch rửa giải vào 30 ống nghiệm, mỗi ống $2 \mathrm{ml}$. Kết quả chạy TLC của tất cả các ống cho thấy từ ống 12 đến ống 18 và từ ống 19 đến ống 30 khớp với các băng trong dịch kháng sinh. Dịch rửa giải của ống 12 - 18 (phân đoạn 2) và $19-30$ (phân đoạn 1) được thu hồi sau chạy sắc kí cột và được tiến hành cất quay loại dung môi thu kháng sinh đậm đặc. Kết quả kiểm tra hoạt tính kháng sinh của hai phân đoạn trên $S$. aureus TCV được thể hiện trên hình 3. 


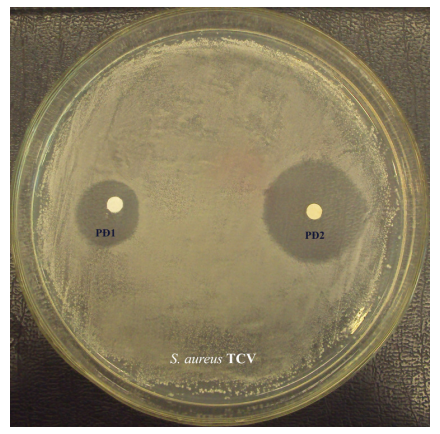

Hình 3. Hoạt tính kháng $S$. aureus TCV của kháng sinh PĐ1 và PĐ2 từ Streptomyces sp. QN63

Với kết quả này, chúng tôi quyết định sử dụng phân đoạn 2 để phân tích cấu trúc hóa học.

\subsection{Kết quả xác định cấu trúc kháng sinh}

Sau khi tinh sạch được hợp chất kí hiệu KS1QN63 (20 mg) chúng tôi tiến hành ghi phổ cộng hưởng từ hạt nhân một chiều ${ }^{1} \mathrm{H}$ NMR trong dung môi $\mathrm{CDCl}_{3}$. Kết quả cho thấy hợp chất này có các tín hiệu của hidro ở vùng trường yếu từ 6 đến $9 \mathrm{ppm}$. Đây là vùng của các nguyên tử $\mathrm{H}$ gắn với cacbon không no và nhóm $\mathrm{N}-\mathrm{H}$. Ngoài ra còn có nhiều tín hiệu ở vùng 3,5 - 4 ppm, gợi ý rằng đây là của các nguyên tử $\mathrm{H}$ có trong proline. Ngoài ra còn có các tín hiệu của các nhóm metyl $\mathrm{CH}_{3}$ - ở vùng từ $0,8-1,4$ ppm có dạng doublet (vân đôi) chứng tỏ trong phân tử có các mắt xích là alanine, leucine hoặc valine.

Kết hợp với việc phân tích phổ ${ }^{13} \mathrm{C}$ NMR chúng tôi thấy rằng hợp chất này có một số nhóm cacbonyl dưới dạng CO-NH từ 165 đến 171 ppm. Có 3 tín hiệu ở 127, 129 và 135 ppm, đây là các cacbon trong nhân thơm, từ đó có thể dự đoán rằng trong hợp chất này có mắt xích là phenylalanine. Không có các tín hiệu ở vùng từ 70 - 90 ppm chứng tỏ trong hợp chất này không có các nguên tử cacbon đính với oxy hoặc $\mathrm{OH}$ bằng các liên kết đơn. Ngoài ra còn có nhiều tín hiệu từ 14 ppm tới 20 ppm là của các nhóm metyl.

Qua việc phân tích phổ cộng hưởng từ hạt nhân ${ }^{1} \mathrm{H}$ và ${ }^{13} \mathrm{C} \mathrm{NMR}$, kết hợp với việc chạy sắc kí bản mỏng và sắc kí cột với hệ dung môi không quá phân cực (5\% metanol trong ethylacetate), chúng tôi dự đoán hợp chất này là một peptit dạng vòng. Tuy nhiên, hợp chất này còn lẫn các cấu tử khác do trong phổ cộng hưởng từ hạt nhân NMR còn có các tín hiệu nhỏ. Qua kết quả chạy sắc kí bản mỏng chúng tôi thấy nó là một chấm tương đối tròn. Do đó không thể tinh sạch bằng sắc kí cột thường được.

Chúng tôi tiến hành đo phổ khối phân giải cao FT-ICR-MS (hình 4). Kết quả trên phổ đồ cho thấy hợp chất này còn lẫn các tạp chất khác. Qua phân tích chúng tôi thấy có đỉnh ion phân tử ở $\mathrm{m} / \mathrm{z} 668[\mathrm{M}+\mathrm{H}]^{+}$, như vậy hợp chất mà chúng tôi tinh sạch được sẽ có khối lượng phân tử là $\mathrm{m} / \mathrm{z} 667$. 


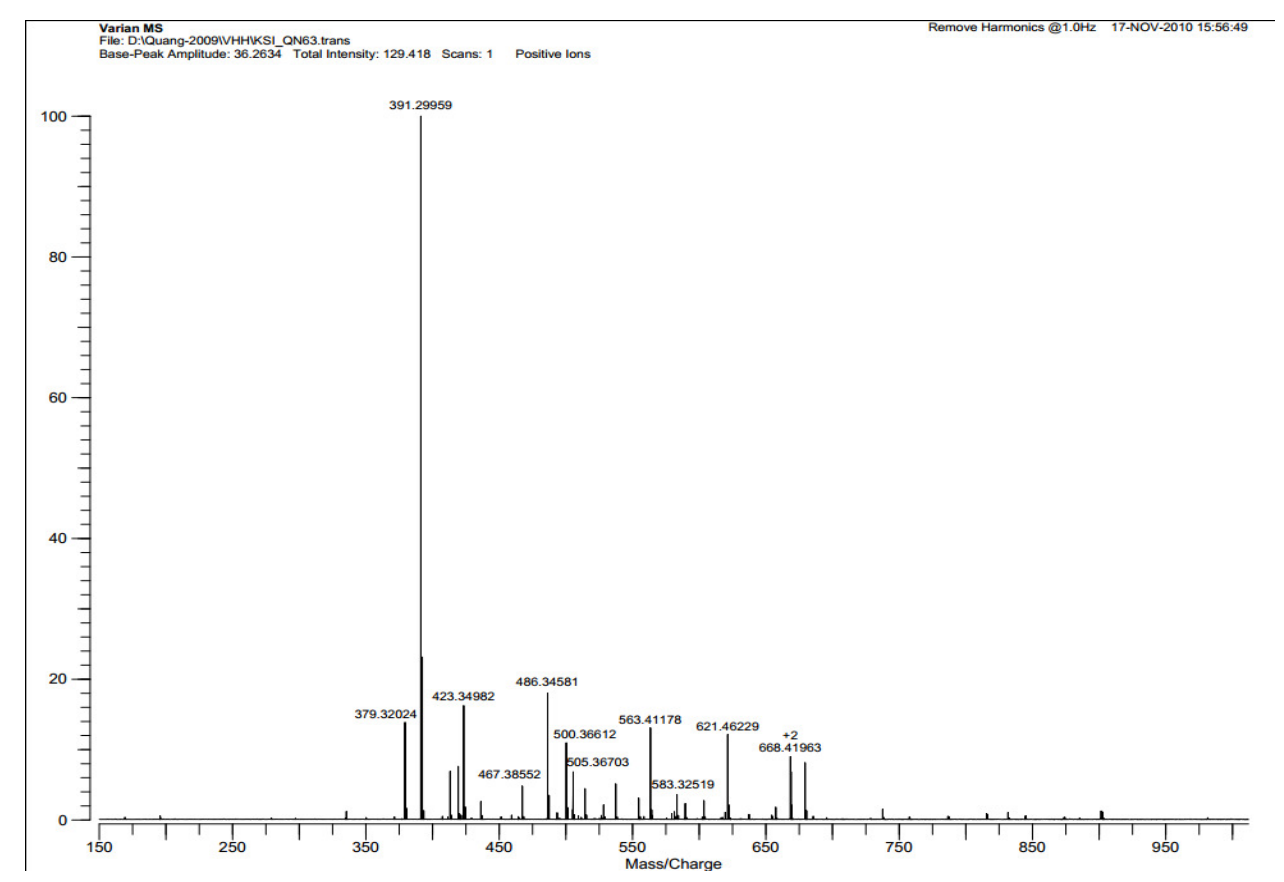

Hình 4. Phổ khối lượng (MS) của phân đoạn 2 kháng sinh từ Streptomyces sp. QN63.

Bằng các phân tích phổ trên, chúng tôi tạm thời sơ bộ kết luận hợp chất phân đoạn 2 của kháng sinh do Streptomyces sp. QN63 là một peptit dạng vòng có khối lượng phân tử là 667 , trong phân tử có các mắt xích là phenylalanine, alanine, leucine (hình 5).

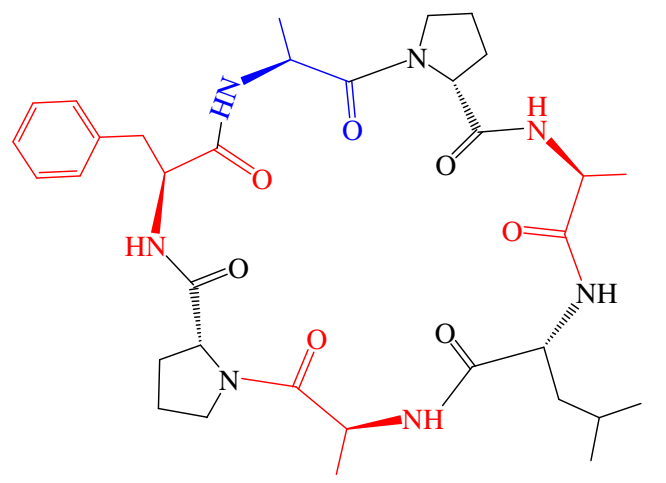

Hình 5. Cấu trúc sơ bộ của hợp chất PĐ2 của kháng sinh từ Streptomyces sp. QN63.

\section{KẾT LUẬn}

Kháng sinh do chủng xạ khuẩn Streptomyces sp. QN63 sinh ra có phổ kháng khuẩn rộng nhưng không kháng nấm. Thành phần của kháng sinh bao gồm hai phân đoạn (PĐ1 và PĐ2) trong đó $\mathrm{PĐ} 2$ có khả năng kháng Staphylococcus aureus mạnh hơn. Các kháng sinh này được tách chiết hiệu quả nhất khi sử dụng dung môi ethylacetate (tỉ lệ 1,5 dịch nuôi cấy/5 dung môi). Kết quả phân tích bổ cộng hưởng từ hạt nhân và phổ khối xác định được kháng sinh phân đoạn 2 là một peptide dạng vòng. So sánh với ngân hàng cấu trúc các hợp chất cho thấy PĐ 2 có thể là 
một kháng sinh mới. Những nghiên cứu về đặc điểm tác động lên tế bào và lâm sàng cần được tiếp tục tiển hành.

\section{TÀI LIỆU THAM KHẢO}

1. Wild D. J., Ding Y., Sheth A. P., , Harland L., , Gifford E. M., and Lajiness M. S. Systems chemical biology and theSemantic Web: what they mean for the future of drug discovery research (2012) doi:10.1016/j.drudis.2011.12.019.

2. Choi W. T., Duggineni S., Xu Y., Huang Z. and An J. - Drug Discovery Research Targeting the CXC Chemokine Receptor 4 (CXCR4), J. Med. Chem. 55(3) (2012) 977994.

3. Hiramatsu K., Hanaki H., Ino T., Yabuta K., Oguri T. and Tenover F. C. - Methicillinresistant Staphylococcus aureus clinical strain with reduced vancomycin susceptibility, Journal of Antimicrobial Chemotherapy 40 (1997) 135-136.

4. Silvestri L., Milanese M., Oblach L., Fontana F., Gregori D., Guerra R. and van Saene H. - Enteral vancomycin to control methicillin-resistant Staphylococcus aureus outbreak in mechanically ventilated patients, American Journal of Infection Control 30 (2002) 391399.

5. Richardson A. R., Libby S. J. and Fang F. C. - A Nitric Oxide-Inducible lactate dehydrogenase enables Staphylococcus aureus to rsist innate immunity, Science 319 (2008) 1672 - 1676.

6. Kirchner J. G., Miller J. M. and Keller G. J. - Separation and identification of some terpenes by a new chromatographic technique, Anal. Chem. 23 (1951) 420-425.

7. Ettre L. S. and Wixom R. L. - Palmer and the beginnings of chromatography in the USA, Chromatographia 37 (1993) 659-668.

8. Đào Đình Thức - Một số phương pháp phổ ứng dụng trong hóa học, NXB ĐHQG Hà Nội, 2007.

9. Augustine S. K., Bhavasrs S. P. and Kapadnis B. P. - A non-polyenee antifungal antibiotic from Streptomyces albidoflavus PU 23", J. Biosci. 30 (2) (2005) 201-211.

\section{ABSTRACT \\ ISOLATION, PURIFICATION AND CHARACTERIZATION OF PENICILLIN-RESISTING STAPHYLOCOCCUS AUREUS INHIBITING ANTIBIOTIC FROM STREPTOMYCES SP. QN63}

Duong Minh Lam*, Dang Ngoc Quang, Nguyen Thi Ha

Hanoi National University of Education

"Email: duong.minhlam@gmail.com

The strain Streptomyces sp. QN63 which was isolated from mangrove soil showed high antagonistic ability on penicillin-resisting Staphylococcus aureus. The antibiotic from this strain 
was thermostable. In this study, we used microbiological and biochemical methods for estimating the antibiotic activity range of the crude antibiotics solution. The isolation, purification and structuralization of the antibiotic were taken. The results showed that the crude antibiotics had wild range of bacterial antagonistic ability (on both Gram positive and Gram negative bacteria) but it did not have and inhibiting activity against tested fungi. The antibiotic composes of two fragments (PĐ1 and PĐ2) in which PĐ2 showed higher bacterial antagonistic ability. The cyclic peptide structure of the $\mathrm{PÐ} 2$ was clarified by using both magnetic nuclear resonance of $\mathrm{H}$ and $13 \mathrm{C}$ and massive charge measurements.

Keyswords: Streptomyces sp. QN63, Staphylococcus aureus, antibiotic resistance, new antibiotics. 